\title{
A INCÔMODA REPRESENTABILIDADE DA FIGURABILIDADE EXPULSA ABJETA, MAS NÃO ANIQUILADA
}

\author{
The uncomfortable representation of the abject and expelled figure, \\ but not exterminated
}

Rubra ARAUJO

Universidade Federal do Tocantins araujorubra@gmail.com

[é] o seguinte, meus senhores: não vamos enlouquecer, nem nos matar, nem desistir. Pelo contrário: vamos ficar ótimos e incomodar bastante ainda. Caio Fernando Abreu.

O propósito deste texto é emergir discussões a cerca de pautas consideradas tabus e que muitas vezes, a sociedade vigente opta por silenciar-se a respeito dessas questões, em uma nítida atitude de abjeção, omissão ou mesmo aquiescimento diante de exclusões históricas que alijam, cotidianamente, pessoas e grupos socioculturais, marginalizados e minorizados em direitos humanos inalienáveis. Comungo, neste texto, do pensamento da filósofa Judith Butler (2002) de que as pessoas invisibilizadas ou que não dispõem de oportunidade de representar a si mesmas são, muitas vezes, consideradas inumanas ao longo da história.

Vivemos, atualmente, em uma sociedade marcada pela noção de identidade e diferença. As pessoas não são hegemonicamente iguais, são dotadas de diferentes questões e/ou marcadores sociais, como raça, origem/classe social, orientação sexual, identidade de gênero, entre outras. Segundo Henry Giroux (1986, p. 32), “identidades práticas têm sido construídas como parte de uma pedagogia em que a diferença se torna base para a solidariedade e a cidadania, e não para a competição e a discriminação". Nesse sentido, notamos que o autor menciona duas possíveis orientações para a dinâmica social da diferença, uma voltada para a solidariedade humana e o exercício da cidadania e a outra para a competição e a discriminação. Na sociedade em que vivemos, apesar da diferença ser parte constituinte do ser humano, infelizmente, tem sido direcionada para o viés da 
competição e da discriminação.

As pessoas são notadamente discriminadas pela cor da pele, pelo jeito de ser, modo de falar, andar, pela classe social, orientação sexual e outras inúmeras performances que nem sempre seguem um padrão hegemônico. As diferenças de identidade de gênero não binário e dissidências da heteronormatividade e outros fatores preponderantes no quesito do padrão branco, eurocentrado, cristão, cisgênero e heterossexual fazem do Brasil um país campeão em que assassinatos motivados por racismo, homofobia, misoginia, intolerância religiosa e outros preconceitos banais (ANTRA/IBTE, 2020).

Segundo o relatório anual do Grupo Gay da Bahia/GGB ${ }^{1}$, organização não Governamental que realiza a catalogação dos crimes homofóbicos no país e age em defesa dos direitos humanos das pessoas LGBTQI+, desde 1980, há notificações anuais de registros de assassinatos de gays, lésbicas, bissexuais e transgêneros em todas as regiões geográficas do país.

Sendo assim, podemos comprovar que a diferença, seja racial e, sobretudo de orientação sexual ou identidade de gênero, tem sido fator preponderante que desencadeia $o$ ódio e aversão às pessoas, tornando-as corpos abjetos, seres que a sociedade civil não tolera e considera descartáveis.

Segundo Judith Butler (apud PRINS; MEIJER, 2002, p. 161), “recebemos uma produção diferenciada ou uma materialização diferenciada do humano. E também recebemos [...] uma produção do abjeto". Como processo discursivo, a abjeção "relacionase a todo tipo de corpos, cujas vidas não são consideradas 'vidas' e cuja materialidade é entendida como "não importante"” (p. 162). Nesse sentido, podemos afirmar que o abjeto designa aqui precisamente aquelas

zonas "inóspitas" e "inabitáveis" da vida social, que são, não obstante, densamente povoadas por aqueles que não gozam do status de sujeito, mas cujo habitar sob o signo do "inabitável" é necessário para que o domínio do sujeito seja circunscrito (BUTLER, 2000, p. 155).

Notamos que corpos ditos abjetos consistem em indivíduos que são ignorados e rejeitados na e pela sociedade, a qual exerce um verdadeiro projeto de assepsia dessas pessoas. Mediante o preconceito e a discriminação, suas vidas não têm valor de dignidade

\footnotetext{
${ }^{1}$ Disponível em: <https://grupogaydabahia.com.br/>. Acesso em: 07 set. 2020.
} 
humana. Esses sujeitos são repudiados porque há um "padrão sociocultural" que se supõe que todos deveriam seguir. Aquele indivíduo que não conseguir segui-lo, não será aceito, ocasionando, assim, a sua exclusão social. Dentre esses sujeitos podemos inserir os homossexuais, os negros, as mulheres, os não cristãos e as pessoas das classes menos favorecidas, sobretudo aqueles que habitam nas zonas periféricas dos centros urbanos. Notamos que quando acontece algum crime em que a vítima faz parte desse grupo de pessoas, os meios de comunicação não costumam realizar uma cobertura devida que retrate a indignação pela violação do direito inalienável da vida. Geralmente, fatos que envolvem corpos que não pesam ou indóceis, nos dizeres de Butler (2000, 2002) e Foucault (1988), são considerados insignificantes, por não interessarem à elite da dinâmica social.

Para Julia Kristeva, em seu livro Poderes do horror (1982), o abjeto é próprio do ser humano, porém este o rejeita porque o considera arcaico e primitivo. Dessa forma, o abjeto é fronteira, marginalizado e coexiste entre o eu e o outro, tornando-se a ambiguidade intolerável e representando discursivamente como o não dito (silenciado, invisibilizado) ou mal dito.

De acordo com o artigo $5^{\circ}$ da Constituição Federal Brasileira (BRASIL, 1988), carta magna que rege a legalidade da vida individual e social em nosso país, "todos são iguais perante a lei, sem distinção de qualquer natureza, garantindo-se aos brasileiros e aos estrangeiros residentes no País a inviolabilidade do direito à vida, à liberdade, à igualdade, à segurança e à propriedade". Entretanto, na prática cotidiana, notamos que esta lei não se efetiva em muitos casos em que as vítimas são os corpos abjetos mencionados anteriormente que, na maioria das vezes são vítimas em potencial de discriminações motivadas devido a ideia de esses corpos destoam dos padrões estabelecidos socialmente para raça, etnia, gênero, orientação sexual, classe social, etc.

Sendo assim, propomos repensar a premissa legal do princípio da democracia, sobretudo o que ampara legalmente a Constituição Federal Brasileira, o qual ressalta a igualdade como fundamental, independente de marcadores sociais ou traços identitários.

Nesse sentido, propomos discutir questões de gênero atreladas a uma perspectiva da diversidade sexual, sobretudo no que concerne a uma abordagem da transgeneridade, enquanto identidade de gênero dos sujeitos em seus processos idiossincráticos de 
subjetivação.

A discussão proposta aqui parte da premissa de diferenciação entre sexo e gênero e vislumbra o gênero na dimensão sociocultural, sendo construído histórico e socioculturalmente pelos indivíduos. De antemão, é importante posicionar neste texto o fato de que "a sexualidade é, sobretudo, (e felizmente!) algo que nos dá prazer e gozo" (PERUCCHI, 2014, p. 3), ou seja ampliamos a concepção de sexo criacionista, com fins reducionistas apenas para a procriação. Sendo assim, atrelamos a ideia de gênero a um sujeito "gendrado", ou seja, indissociável da ideia de gênero. Nesse sentido, essa discussão torna o sujeito envolto em "uma ação política, múltipla de significados" (PERUCCHI, 2014, p. 3). Neste processo representacional, é importante ressaltar as relações assimétricas, sobretudo no que toca à depreciação e subalternização do gênero feminino como submisso ou inferior ao sexo e gênero masculino, considerado público e detentor de privilégios.

Mediante convicção própria, leituras e fatos, ousamos a afirmar que a homo/transfobia é altamente misógina, ou seja, na negação da homossexualidade ou transexualidade masculina, o que se nega veementemente é o feminino e suas múltiplas representações. Mediante tal afirmativa, deparamo-nos com dados estatísticos de assassinatos cruéis de travestis e transexuais, tornando o Brasil campeão nesses desdobramentos de crimes de ódio, caracterizando verdadeiras barbáries contra esse segmento populacional (ANTRA/IBTE, 2020). Na intersecção desses dados, há a nítida violência doméstica contra as mulheres, crianças e idosos que cresce vertiginosamente, sobretudo nesse período de pandemia que o país atravessa ${ }^{2}$.

Estas configurações socioculturais que assolam e subjugam vidas no cenário político, científico e representacional ocasionando invisibilidade de muitos torna premente repensar a possibilidade de pautas de discussões socioculturais, seja na esfera acadêmica, familiar, midiática ou até mesmo religiosa. Tais medidas tornam-se necessárias no sentido de sensibilização para a necessidade e o dever de inclusão de todas e de todos.

Geralmente por ocasiões de datas comemorativas alusivas ao contexto familiar tradicional, como dia dos pais e/ou dia das mães surgem algumas polêmicas de ordem

\footnotetext{
${ }^{2}$ Notícias vinculadas ao Observatório da Mulher contra a Violência (OMV). Disponível em: $<$ https://observatorio3setor.org.br/podcast/violencia-contra-a-mulher-durante-a-pandemia/ $>$. Acesso em: 28 ago. 2020.
} 
conservadora nos meios midiáticos. Na maioria dessas discussões, emergem visíveis discriminações de homo/transfobia e muitas discussões da representação de paternidade ou maternidade atrelada a uma visão bioessencialista.

O interessante a observar é que nessas reivindicações de ordem conservadora e patriarcal contra as configurações familiares emergentes - homo/transparentais consideradas pela sociedade tradicional como questões abjetas, não se coloca em xeque, por exemplo, as necessidades vitais da criança que necessita de acolhimento e amor, a homo/transfobia se manifesta assim de forma explícita. Segundo informações disponibilizadas no Instituto Brasileiro de Direito de Família/IBDFAM ${ }^{3}$, são 5,5 milhões de crianças sem o nome do pai no registro de nascimento e, quando surge um caso de um pai de identidade de gênero não padrão que assume a responsabilidade paterna, o mesmo é rechaçado e apontado como algo inaceitável por certos representantes de instituições conservadoras.

Temos que considerar, por fim, que "onde há poder, há resistência" (FOUCAULT, 1988, p. 104) e, nesse contexto, é importante observar que nos momentos cruciais de opressão pelo sistema vigente, manifestaram grandes produções artísticas e, sobretudo, ideias libertárias no sentido de promover cenários mais propícios de opções amplas, diversas e plurais, sem tantas pressões e moldes ultrapassados que aprisionam vidas.

\section{REFERÊNCIAS}

ANTRA/IBTE. Dossiê dos assassinatos e da violência contra travestis e transexuais brasileiras em 2019. Bruna G. Benevides, Sayonara Naider Bonfim Nogueira (Org.). São Paulo: Expressão Popular, 2020.

BRASIL. Constituição da República Federativa do Brasil. Brasília, DF: Senado Federal: Centro Gráfico, 1988.

BUTLER, J. Cuerpos que importan: sobre os limites materiales y discursivos del "sexo". Buenos Aires: Paidós, 2002.

BUTLER, J. Corpos que pesam: sobre os limites discursivos do "sexo". In: LOURO, G. L.

\footnotetext{
${ }^{3}$ Disponível em:

$<$ https://ibdfam.org.br/noticias/7024/Paternidade+respons\%C3\%A1vel:+mais+de+5,5+milh\%C3\%B5es+de

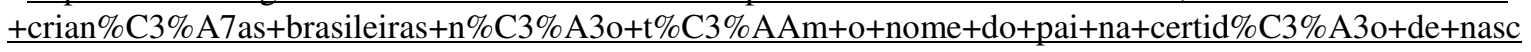
imento >. Acesso em: 28 ago. 2020.
} 
(Org.) O corpo educado - Pedagogias da sexualidade. Belo Horizonte: Autêntica, 2000.

DECLARAÇÃO UNIVERSAL DOS DIREITOS HUMANOS, 1948. Disponível em: $<$ https://nacoesunidas.org/wp-content/uploads/2018/10/DUDH.pdf $>$. Acesso em: 20 jun. 2016.

FOUCAULT, M. História da Sexualidade: A Vontade de Saber. Rio de Janeiro: Graal, 1988.

GIROUX, H. Teoria crítica e resistência em educação: para além das teorias da reprodução. Rio de Janeiro: Vozes, 1986.

KRISTEVA, J. Powers of horror. Nova York: Columbia University Press, 1982.

PERUCCHI, J. Prefácio. In: JESUS, J. G. de (Org.) Transfeminismo: teorias e práticas. Rio de Janeiro: Ed. Metanoia, 2014.

PRINS, B.; MEIJER, I. C. Como os corpos se tornam matéria: entrevista com Judith Butler. Revista Estudos Feministas [online] v.10, n.1, p.155-167, 2002. 